\title{
Impact of Global Changes of the Pandemic Crisis on Business Models of Transport Companies
}

\author{
Natalia Zhuravleva ${ }^{1, *}$, and Liana Chechenova ${ }^{2}$ \\ ${ }^{1}$ 190031, Russia, Saint Petersburg, Emperor Alexander I St Petersburg State Transport University
}

\begin{abstract}
.
Research background: The coming period of the world economy coming out of the pandemic crisis will seriously change the situation in the cargo and passenger segment. According to the assessment of the current situation, in the global market there is a violation of the usual ties between producers and consumers, an imbalance in transport flows associated with changes in demand. At the same time, in a crisis, rail transport is the main tool, since a significant amount of anti-epidemic protective equipment from China was transported by trains. It is clear that in the near future the dynamics of the market depends, first of all, on the further development of events and measures of state support for industries and businesses. Purpose of the article: The purpose of this research is to score the factors of the post-crisis state of transport sector: alterations in the gravity of commodity markets, modifications of valuable preferences assessment of the shipper and the passenger, that change the business model of transport companies.

Methods: Standard methods of scientific research are used: theoretical and experimental; complex methods of analysis and evaluation of business models: a complex scheme for developing a business model, a canvas and a conceptual scheme of a business model; methods of qualitative data analysis.

Findings \& Value added: Factors changing the transport business model are systematized. The research estimates a change probability in the gravity of commodity markets towards Asian countries, the consequences of the influence of digital technology on the efficiency of the transport business and the shift in the value of transport services in the line of high speeds. It shows the impact of the post-pandemic economy, which has formed new habits, passenger behavior on passenger companies' operations. The research justified crisis effects resulting in the deterioration of the competition in the transport markets.
\end{abstract}

Keywords: COVID-19 economics; operational and business models of transport companies; the value of transport service; rational behaviour

${ }^{*}$ Corresponding author: zhuravleva na@mail.ru 
JEL Classification: $G 1 ; M 21 ; L 92$

\section{Introduction}

Any company either creates added value, joining the post-pandemic economy, or is forced to leave the market. Today, companies focused on tangible products are looking for ways to complement them with new properties, trying to enter new markets. Transport companies that sell transport services are forced to significantly change the way they are provided and supplement them with new services. New properties or services are provided by digital transformation, business diversification, personalization of goods or services, forms of business organization based on cost optimization, or any other changes in operating and business models that contribute to increasing profits. Companies that fail to do so will be squeezed out of the market or significantly reduce their activities. This is true even for such giant companies as Russian Railways, all the more so for freight and passenger operators in the rail transport market. Already before the crisis, there was a dominant tendency to move away from single-type competition - competition between certain modes of transport towards multimodal (mixed) competition for cargo, route, passenger - the current situation will accelerate this process and cause increased concentration of business.

At the same time, in the technical and economic literature, most forecasts of the future of the transport system, both global and national ones, describe the development of existing modes of transport. It is believed that transport systems should increase the speed and frequency of transportation, as well as increase the number of transport services. These plans for the future are complemented by measures aimed at improving the level of environmental protection: less fuel, less $\mathrm{CO} 2$, more public transport. However, these visions of the future usually assume that the mobility of people and goods after the end of the pandemic will continue to grow at a pre-crisis rate. Having conducted a study of the behavior of consumers of transport services - cargo owners and passengers, we present a slightly different point of view on the future of transport systems.

The main reasons that allowed us to make these assumptions are related to the fact that:

- one third of the world's population can be blocked for a short time indefinitely. For any transport business model with a high proportion of fixed costs, this is a significant threat $[1,2]$;

- the uncontrolled growth of unemployment is obvious, i.e. structural unemployment (associated with the replacement of part of the professions) will be joined by unemployment in the spheres of activity associated with contacts between people [3]. This is followed by the bankruptcy of entire industries, which in turn are consumers or producers in the chains of creating certain goods and services for transport companies;

- geopolitics will change: border closures, restrictions in the international division of labor, sanctions, changes in customs rules, etc. [4]. For a transport business model based on transport infrastructure, a change in the gravity of commodity and passenger flows means an increase in costs across the entire range of costs while reducing revenues from traditional activities.

Unfortunately, it is impossible to return to normal life in the previous format, which was in December 2019. Consequently, the need to assess the impact of the factors of the postcrisis economy on the business model of transport companies is obvious.

The object of this study is the business model of railway transport companies, and the subject is analytical procedures for the impact of global trends in the post-pandemic economy changes on the operational and business activities of transport companies. 


\section{Methods}

The business model of a company is a set of its processes by which it creates values (products, services), delivers them to the market and receives reciprocal values (money, technology, reputation, etc.) [5]. In our description of the business model, we will restrict ourselves to its four main parts: value proposition, profit formula based on the revenue model, cost structure, profit margin and operating cycle speed, key resources and key processes [6]. It is these blocks of the business model that are subject to the maximum impact of changes in the gravity of commodity markets, changes in the value preferences of the shipper and passengers, and the emergence of new types of competition in transport markets.

Using the theory of rational behavior, it can be said that in the current situation, the model of human behavior is shifting towards maximizing utility (including previously unknown values) in conditions of limited resources. This means that the choice of a product or service is solely caused by its value (utility) and becomes a purely „economic choice“. Thus, passengers strive to ensure the monetization of their mobility, transport companies to optimize costs and stay in their market segment, the state pursues various, often contradictory goals related to ensuring stability, economic efficiency, socio-economic equality of society members, etc. Obviously, the rationality of behavior will lead to a change in the value of the transport service: there are obvious examples of violation of the rationality of behavior during the period of isolation and the uncertainty of getting out of it, which directed attention to the search for an assessment of new psychological factors that change the behavior of consumers of transport services, transport companies and the Russian regulator [7, 8, 9].

We made a forecast of changes in the concentration of companies in the Russian rail transportation market in the cargo transportation segment. Using the Herfindahl-Hirschman Index (HHI) and the Top 30 rolling stock operators [10], we recorded the desire of the largest operators to monopolize the market.

In assessing the factors influencing the change in the gravity of commodity markets, we used the study „Freight transport links between China and Europe in the context of the spread of coronavirus: risks and consequences" carried out by the Eurasian Rail Alliance Index in March 2020 [11].

\section{Results}

\subsection{Factors that significantly change the freight business model}

The business model of a transport organization presupposes three fundamental forms of activity: a customer-oriented business, an innovation-oriented one, and an infrastructureoriented one. These forms of activity exist, for example, within Russian Railways, but ideally, the infrastructure should be conditionally "separated" in order to avoid conflicts in the transport market or unwanted monopolization of certain types of transport services.

The defining factor affecting the business model of freight transportation by rail is the shift in the volume and nomenclature of freight traffic. It is already obvious that the countries of Asia are becoming significant beneficiaries of the pandemic crisis, whose outstripping development will attract new commodity flows and form new active commodity markets. So, for example, China, to which up to $80 \%$ of the production of individual industries was transferred, using the most modern technologies, can switch to a closed production cycle and consume only the necessary minerals and energy resources from foreign markets. And the chain reaction of shifting commodity markets will only 
grow. There is a serious threat that the quantity and quality of transport services will lag behind the transportation requirements for active commodity markets. The main risk for the transport system is the inability to quickly change its infrastructure. Highways and railways, seaports, airports, etc. created for a specific structure of the world economy, the system of international and national division of labor cannot change at the same rate as the gravity of commodity markets. Only state, interstate, territorial projects for the development of transport infrastructure can influence the situation in the most mobile way.

Changes in the volume and structure of commodity markets significantly affect the range of cargo transportation. The pace of these changes will be influenced by some digital technologies such as digital twins and 3D printing. By 2020, the digital twin market has reached $\$ 3.8$ billion, entering the segment of real products used by various companies, including industrial ones. It turned out that digital models of products are convenient to use within the framework of automated production controlled by a computer, i.e. according to the digital model, a robot of any complexity can assemble the product itself. And in the last ten years, with the advent of the Internet of Things, many physical products connect to the Internet, supplying data about their functioning to the global network. This data can be used to make the digital model of any product correspond to a real object. At this moment, the digital twin appears. It can be of independent value to the consumer, and in combination with 3D printing technology, provide the production of tools and parts, organic imitators; prototypes and everything that the consumer requires. Thus, parts can be quickly fabricated on site, eliminating long waiting times for shipment and significantly reducing shipping costs. We have seen how these technologies have made it possible to instantly tune the production of protective materials during an epidemic, providing tremendous profitability to their manufacturers. Thus, the manufacturer approaches the consumer as much as possible, and raw materials, fuel and other resources begin to dominate in the range of goods. By 2025, according to Markets and Markets, the volume of digital twins alone will increase to $\$ 35.8$ billion.

The most significant impact on transport was provided by the Supply Chain 4.0 technology. The COVID-19 pandemic has disrupted the global supply chain, and some factories have completely closed. Although the demand for food and personal protective equipment is growing, some countries have imposed various bans on the export of such products. The heavy reliance on paper documents and the lack of data transparency made the existing supply chain system vulnerable to a pandemic $[12,13]$. The main technologies of the fourth industrial revolution, such as big data, cloud computing, Internet of Things (IoT) and blockchain, create a more sustainable supply chain management system $[14,15]$.

How will this change the business models of transport organizations? Now it is not enough for technologies to be focused only on the growth of the company's technological potential and innovativeness of its solutions. The use of any technology should be associated with the solution of complex social problems and tasks, be accompanied by a reduction in costs and ensure the „survival“" of the business in times of global turmoil.

For transport systems and, above all, railway organizations, high-speed transportation with a speed of over $500 \mathrm{~km} / \mathrm{h}$ is becoming a generator of growth in the efficiency of their business models in the post-crisis economy. This is especially noticeable at the pace that the PRC is pursuing. Thus, the Chinese government is promoting infrastructure projects to revive the economy based on the high-speed maglev train. Despite the fact that these projects are primarily related to passenger transportation, freight transportation using magnetic levitation trains will, in principle, be possible. Options for the transportation of high-quality goods with low weight and sensitive to the time spent on delivery are considered. In general, fantastic transport projects appear and are seriously discussed, such as the use of new generation airships. In 2016, a dozen LMH-1 hybrid airships (to appear in 2020-2021) were ordered from Lockheed Martin for almost \$500 million. The customer 
planned to hand over the vehicles with a lifting capacity of 20 tons to oil and gas companies in the Arctic. Of course, these vehicles are not ideal. They are slower than planes and helicopters (albeit faster than cargo ships), and their sheer size makes them vulnerable to high winds and other adverse weather conditions. But renting an airship is cheaper than building roads in the permafrost zone, which is also melting due to global warming. And about seven times cheaper than using large-capacity helicopters. Since China and other countries are using more and more remote territories in search of natural resources, airships can become an important link in supply chains [16].

Thus, the operating and business models of transport organizations are revising their strategic settings, focusing their business on technological solutions that directly affect effective changes associated with optimizing costs and increasing their competitiveness.

\subsection{New business model for passenger transportation in a post-pandemic economy}

The biggest impact on the business model of passenger transport companies is being driven by the massive shift towards the digital world, accelerated by the pandemic crisis. Human behavior has changed significantly: two thirds of the world has gone into remote work, distance learning, remote medical consultations, etc. The pandemic has turned online shopping from an alternative into an inevitable shopping option (online shopping and delivery of goods by robots). The most common type of payment is digital and contactless payments (cards or e-wallets). Remote work and distance learning have fueled the explosive development of various technologies such as virtual private networks (VPNs), cloud technologies, virtual reality, augmented reality, 3D printing and robot teachers, facial recognition technologies (which allow a person to appear in front of a virtual background) and etc. Telemedicine has demanded personal medical devices that can track vital signs of a person's health, and bots can make primary diagnoses based on symptoms identified by patients. The online entertainment industry has allowed virtual travel.

The imposition of travel restrictions in response to the pandemic (according to UNWTO, as of April 6, about 96\% of all destinations around the world had imposed restrictions) reduced passenger traffic by $91 \%$. Of course, we see the removing of restrictions, but digital trends are only growing $[17,18]$.

Following early research by B. Chlond, J. Last, W. Manz, D. Zumkeller, showing that most of the population is very little or not at all active in long-distance transport, while only a small part of population has high mobility in relation to long-distance transport [19]. Typically: in international traffic, one percent of all respondents generate about ten percent of all travel; ten percent of all respondents make almost 50 percent of all travel; and 50 percent of respondents generate over 90 percent of all travel. Business travel accounts for $21 \%$ of all long-distance travel, vacations ( 4 nights or more) $-33 \%$, and other private travel $-46 \%$.

This means that remote work, the possibility of holding meetings and conferences online, the preservation of the post-pandemic syndrome of danger of close contacts will not allow restoring all volumes of passenger traffic in the near future.

Adequate knowledge of potential technology trends is an economic issue for business survival, so the decision to join or abandon trends should be based on changes in carriers' business models. It turned out that it is possible to find several major technological trends in the world that remain immune to the epidemic and, moreover, activate the operating and business models of companies - passenger carriers. First of all, what should be the infrastructure of transport systems? How will intermodality, network and client frequency develop in the future if traffic flows are separated by speed rather than by mode of 
transport? The systematization of these and other changes affecting the business models of transport organizations made it possible to form the following dependencies (Fig. 1):

\section{Multifunctionality}

\section{Structuring}

\section{Factors affecting the business model of a transport company}

\section{Changing \\ the competition model}

\section{Efficiency analysis}

Fig. 1. Transformation of the business model of a transport company.

\section{Multifunctionality.}

The development of passenger traffic is possible only in the interconnection of the environmental, economic, social or public dimension. The challenge is to account for the long-term, uncertainty, ambivalence and trends of the current crisis.

Structuring.

Spatial planning should take into account factorial time in general. "Quick accessibility" means frequent travel and the increasing importance of passenger traffic in the spatial network of agglomerations. It means the need to reintegrate goals for the business of transport companies, for the development of territories, for the passenger. Ethical aspects, social values and attitudes must be taken into account [20].

Changing the competition model in the passenger transportation market.

Customer focus becomes a time-based service. A competitive service will not necessarily be passenger transportation.

Efficiency analysis.

Analysis of costs and benefits using the classical methodology for assessing transport projects is insufficient. There is a need for procedures for assessing the „usefulness“ of the trip for the passenger. Our reasoning is confirmed by the fact of development of magnetic levitation passenger transport [21].

As you know, the Chinese state corporation CRRC has been designing this high-speed system based on the German EMS Transrapid technology for several years. The main project is a branch with a length of about $400 \mathrm{~km}$, connecting Shanghai - Hangzhou Ningbo, which should provide a maximum speed of 600 kilometers per hour. Its design cost is about 100 billion yuan (US \$14.1 billion). The project to integrate the maglev high-speed train station into the terminals of Hongqiao Airport has already been completed. (Information presented here is based on unofficial Chinese sources and the Nikkei Asian Review report dated April 17, 2020.). It should be emphasized that the economic effect of the business model of high-speed rail transportation is not provided by energy savings, reduced environmental impact, tracing and other benefits of magnetic levitation, but rather by the high speed of transportation, which ensures monetized mobility of the population and a reduction in the operating costs of the carrier [22]. 


\section{Discussion}

The results of this research are relevant to projects to assess the business-models of organizations providing both freight and passenger transportation. Under the influence of a crisis situation, the economic, social and individual perception of the environment changes. If we talk about the change in the gravity of world commodity markets, then it should be noted that a significant decrease in freight traffic due to a decrease in demand for raw materials. Considering the results of the analysis of the compensating role of the fall in oil prices for the impact of the epidemiological situation on the non-renewable transport sectors of the economy, carried out by L. Aydin and I. Ari [23], we find confirmation that the determining factor that affects the business model of freight transport by rail is the displacement of volumes and nomenclature of cargo flows.

Likewise, in codifying changes affecting the business models of transport organizations, we relied on analyzes carried out for air, freight and urban transport in order to predict short-term implications for the transport system, taking into account the strategies adopted by the governments of different countries [24].

Our conclusion on the impact of the pandemic on industries is supported by the work of Chinese research scientists, who, using event research, studied market performance and trends in the response of Chinese industries to the COVID-19 pandemic. The study showed the negative impact of the consequences of the crisis on the transport, mining, and electric power industries, but at the same time healthcare, information technology and education turned out to be resistant to this phenomenon [25]. In particular, a study by Indian scientists revealed the degree of influence of the global epidemic on labor migration, taking into account the emerging risks inherent in unorganized sectors of the economy, as well as contract workers in many industries, which made it possible to expand the data set of our study [26].

The methods, using for assessing the factors of the post-crisis economy, can be expanded taking into account the results of the methodology for calculating the index of social sustainability of cargo transportation proposed by Kumar, A., Anbanandam, R. The results of the study are significant in solving the problems of social and environmental sustainability faced by many freight carriers [27].

The importance of finding optimal solutions to the problem under study is evidenced by a large number of publications. In particular, the impact of the post-pandemic economy on the business model of transport organizations can be considered in another aspect, namely, how the development of the transport road network, taking into account the spatial differences in the socio-economic status of passenger traffic, affects the spread of pandemic diseases. A. Baveja, A. Kapoor, B. Melamed provides a quantitative assessment of the impact of the road network and socio-economic factors during the outbreak, the results of which support our conclusions regarding changes in the model of competition in the passenger transport market. Scientists propose a plan "Shutting-down Transmission of Pandemic", based on the principles of the theory of limitations, which aims to mitigate the economic impact of the crisis, taking into account the added value of services to control the spread of the epidemic [28]. In general, a significant amount of research on the impact of the post-pandemic economy on the business model of transport organizations indicates the high relevance of this topic and, thereby, encourages to consider it as a signal for strategic coordination of the economy and market needs. 


\section{Conclusion}

The greatest attention in the freight and passenger transport market deserves not so much the crisis phenomena from COVID-19, but their combination with such factors as the instability of the hydrocarbon market, the shift of the poles of the main commodity markets and the means of communication between them, the volatility of the financial market - how likely is it to create the necessary conditions for a full-scale deep crisis, taking into account the accumulated problems in the world economy.

Predictive models [29,30] indicate that the world economy, even before the epidemiological crisis, entered the phase of a cyclical (structural) crisis. The situation is complicated by new factors of uncertainty, such as: the duration of the quarantine and the possibility of its multiple introduction during the year; the scale and duration of government responses, changes in human behavior and preferences, and, finally, the depth of the economic crisis and the profile of recovery from it.

The operating and business models of transport companies are most susceptible to these influences. This explains the need for their ,adaptability“ to such conditions and the search for ways to maintain and optimize the business.

\section{References}

1. Debata, B., Patnaik, P., Mishra, A. (2020). COVID-19 pandemic! It's impact on people, economy, and environment. Journal of Public Affairs, article № e2372.

2. Iacus, SM., Natale, F., Santamaria, C., Spyratos, S., Vespe M. (2020). Estimating and projecting air passenger traffic during the COVID-19 coronavirus outbreak and its socio-economic impact. Safety Science, 129(104791).

3. Bashir, MF., Ma, B., Shahzad, L. (2020). A brief review of socio-economic and environmental impact of Covid-19. Air Quality, Atmosphere and Health.

4. Benedicto Solsona, MA., Molina Garcia, MJ. (2020). Facing the current challenges of global geopolitics, how is the strategic autonomy of the European Union articulated in the framework of its foreign and security policy? Relations Internacionales, 44, 11-28.

5. Zhuravleva, NA. (2018). Metodologiya issledovaniya cifrovoj transformacii $v$ usloviyah destabilizacii biznes-modelej transportnyh organizacij. In: Babkin $A V$, editor. Metodologiya Razvitiya Ekonomiki, Promyshlennosti i Sfery Uslug v Usloviyah Cifrovizacii (pp. 10-47). St. Petersburg: SPbPU.

6. Johnson, MW., Christensen, CM., Kagermann, H. (2008). Reinventing your business model. Harvard Business Review, 86(12), 50+/-.

7. Kahneman, D., Diener, E., Schwarz N. (eds.) (2003). Well-being: Foundations of hedonic psychology. Russell Sage Foundation.

8. Kahneman, D. (2013). Thinking, fast and slow. Farrar, Straus and Giroux (FSG).

9. Ceder, A. (2020). Urban mobility and public transport: Future perspectives and review. International Journal of Urban Sciences.

10. Hirschman, AO. (1980). National power and the structure of foreign trade. University of california.

11. Eurasian Rail Alliance Index. (2020, March) Freight transport links between China and Europe in the context of the spread of coronavirus: risks and consequences. https://index1520.com/upload/medialibrary/0e6/_4.pdf. 
12. Chiaramonti, D., Maniatis, K. (2020). Security of supply, strategic storage and Covid19: Which lessons learnt for renewable and recycled carbon fuels, and their future role in decarbonizing transport? Applied Energy, 271.

13. Gray, RS. (2020). Agriculture, transportation, and the COVID-19 crisis. Canadian Journal of Agricultural Economics/Revue Canadienne D'agroeconomie, 68(2), 239243.

14. Zhuravleva, N., Guliy, I., Polyanichko, M. (2019). Mathematical description and modelling of transportation of cargoes on the base digital railway. Environment. Technology. Resources: Proceedings of the 12th International Scientific and Practical Conference. T. II. (pp. 175). Rezekne: Latvia

15. Ai, B., Molisch, AF., Rupp, M., Zhong, Z. (2020). 5G key technologies for smart railways. Proceedings of the IEEE, 108(6), 856-893.

16. How airships will change the freight market (2020, June 16). https://pro.rbc.ru/news/5c88fa409a79479a18ded184?from=related_materials.

17. Khodakivskyi, O., Khodakivska, Y., Kuzmenko, O., Shcherbyna, M., Kolesnichenko O. (2019). Improvement of the railway transport system by increasing the level of goal-oriented activity. Procedia computer science, 149, 415-421.

18. Nemtanu, FC., Marinov, M. (2019). Digital railway: trends and innovative approaches. Sustainable rail transport. Lecture Notes in Mobility (pp. 257-268). Cham.: Springer.

19. Chlond, B., Last, J., Manz, W., Zumkeller, D. (2004). Eckwerte des Personenfernverkehrs in Deutschland. Internationales Verkehrswesen, (56)10, 430435.

20. Gallego, I., Font, X. (2020). Changes in air passenger demand as a result of the COVID-19 crisis: using Big Data to inform tourism policy. Journal of Sustainable Tourism.

21. Wu, W., Lu, X., Liu, G., Long, X., Shen, Y. and Liu, Y. (2019). Operation control system of $600 \mathrm{~km} / \mathrm{h}$ high-speed maglev levitated transport system in China. IEEE Vehicle Power and Propulsion Conference (VPPC) (pp. 1-5). Hanoi: Vietnam.

22. Wei, S., Jiao, J., Wang, L., Xu, J. (2020). Evolving characteristics of high-speed railway network structure in Yangtze river delta, China: The perspective of passenger flows. Applied Spatial Analysis and Policy, 13(4), 925-943.

23. Aydin, L., Ari, I. (2020). The impact of Covid-19 on Turkey's non-recoverable economic sectors compensating with falling crude oil prices: A computable general equilibrium analysis. Energy Exploration \& Exploitation, 38(5), 1810-1830.

24. Arellana, J., Marquez, L., Cantillo, V. (2020). Covid-19 outbreak in Colombia: An analysis of its impacts on transport systems. Journal of Advanced Transportation, article №ABB-1372-2020.

25. He, Pl., Sun, Yl., Zhang, Y., Li, T. (2020). COVID-19's impact on stock prices across different sectors-an event study based on the Chinese stock market. Emerging Markets Finance and Trade, 56(10), 2198-2212.

26. Khanna, A. (2020). Impact of migration of labour force due to global covid-19 pandemic with reference to India. Journal of Health Management, 22(2), 181-191.

27. Kumar, A., Anbanandam, R. (2019). Development of social sustainability index for freight transportation system. Journal of Cleaner Production, 210, 77-92.

28. Baveja, A., Kapoor, A., Melamed, B. (2020). Stopping Covid-19: A pandemicmanagement service value chain approach. Annals of Operational Research, 289(2), 173-184. 
29. Banerjee, N., Morton, A., Akartunali, K. (2020). Passenger demand forecasting in scheduled transportation. European Journal of Operational Research. 286(3), 797-810.

30. Kliestik, T., Valaskova, K., Lazaroiu, G., Kovacova, M., Vrbka, J. (2020). Remaining financially healthy and competitive: The role of financial predictors. Journal of Competitiveness, 12(1), 74-92. 